\title{
Cell death in the avian blastoderm: resistance to stress- induced apoptosis and expression of anti-apoptotic genes
}

\author{
Stephen E. Bloom ${ }^{1,2}$, Donna E. Muscarella ${ }^{1}$, Mitchell Y. Lee ${ }^{1}$ \\ and Melissa Rachlinski ${ }^{1}$ \\ ${ }^{1}$ Department of Microbiology and Immunology, Cornell University, Ithaca, New \\ York 14853, USA \\ 2 corresponding author: tel: 607-253-4041; fax: 607-253-3384; \\ email: seb14@cornell.edu
}

Received 13.11.97; revised 21.1.98; accepted 4.3.98

Edited by C.J. Thiele

\begin{abstract}
We investigated the expression of an apoptotic cell death program in blastodermal cells prior to gastrulation and the susceptibility of these cells to stress-induced cell death. A low frequency $(3.1 \%)$ of apoptotic blastodermal cells was observed in Hoechst 33342-vitally stained cytological preparations of complete blastoderms from unincubated eggs. These cells showed the stereotypic features of apoptosis including a progression of nuclear changes, cell shrinkageand blebbing, and the formation of apoptotic bodies. Prolonged storage of eggs at $12{ }^{\circ} \mathrm{C}$ induced apoptosis in blastodermal cells $(14 \%)$. A modest amount of apoptosis $(10 \%)$ was also induced at the heat shock temperature of $48^{\circ} \mathrm{C}$, but not at $45^{\circ} \mathrm{C}$. Etoposide and other potent cytotoxic drugs failed to induce apoptosis in the blastodermal cells after $4 \mathrm{~h}$ of exposure. Progressively more apoptosis was induced at 8 and $24 \mathrm{~h}$, but it did not exceed $35 \%$ of the cells. We detected transcripts for the anti-apoptotic genes $b c l-2, b c l-x_{L}$, and $h s p 70$. The developmental expression of these genes, especially hsp70, correlated with the delayed and limited stress-induction of apoptosis. These studies reveal the capacity of pre-streak blastodermal cells to engage in apoptosis and their relative resistance to stress conditions. This may be due to the prominent expression of $h s p 70$ and/or multiple cell death genes which primarily antagonize cell death.
\end{abstract}

Keywords: blastodermal cells; apoptosis; heat and cold shock; etoposide resistance; cell death genes, developmental expression

Abbreviations: ETP: etoposide; h: hour; MMC: mitomycin C; PCD: programmedcell death; RT-PCR: reverse transcriptase polymerase chain reaction; STP: staurosporine; TPT: topotecan; VCR: vincristine

\section{Introduction}

Major developmentally-regulated processes in the avian blastoderm include rapid, successive rounds of cell division in cleavage stages and subsequent extensive cell migration in the formation of the initial and primitive streaks (Romanoff, 1960; Eyal-Giladi and Kochav, 1976). Cell death has been shown to occur in regions of gastrulating embryos (Jacobson, 1938; Glucksmann, 1951; Sanders et al., 1997a,b). However, it is unclear whether programmed cell death (PCD) occurs, or is required, at stages preceding gastrulation. In fact, classical reviews of early development in the avian embryo do not mention cell deaths in connection with cleavage division stages, in the formation of epiblast and hypoblast layers of the blastoderm, or in the establishment of polarity in embryos (Romanoff, 1960, 1972; Eyal-Giladi and Kochav, 1976).

An early suggestion of cell death by an apoptotic mode in the blastoderm was provided in the ultrastructural study of unincubated and grastrulating chick embryos (Bellairs, 1961). This work revealed 'chromatic patches' near the nuclear membrane of some cells at both developmental stages. Later, Arora and Kosin (1968) observed 'necrotic nuclei' in blastodermal cells from fresh and cold-stored eggs. Fragmentation of nuclei was mentioned as one characteristic of damaged or dead cells. An increase in the frequency of necrotic nuclei was noted from about $2 \%$ after 1 day, to $4 \%$ of cells after 14 days of storage at $12.8^{\circ} \mathrm{C}$. This work suggested the intriguing possibility that cell death (perhaps by apoptosis) may occur at temperatures well below those that initiate development. This study also suggested that blastoderm senescence during cold storage involves cell 'necrosis', which may be responsible for the subsequent mortality of some embryos during incubation. However, it has yet to be determined whether blastodermal cell deaths occur primarily by apoptosis as contrasted to necrosis. Additionally, the extent of apoptotic cell death among individual early embryos is unknown.

Studies with the early mouse embryo have addressed the issue of whether or not an apoptotic death program is expressed in early embryogenesis. Significantly, staurosporine (STP) induced apoptosis in the majority of cells from mouse embryos at cleavage stages 2-64 (Weil et al, 1996). However, a role for apoptosis in early murine development has not been established. One speculation is that PCD might perform a protective function for the early embryo by eliminating genetically-aberrant blastomeres before they proliferate (Jurisicova et al, 1995; Jacobsen et al, 1997). The capacity and propensity of avian blastomeres to undergo 'spontaneous' or stress-induced apoptosis is presently not known.

Evidence from a number of studies suggests that avian blastodermal cells are resistant to environmental stressinduced cell death. It has been known for many years that blastodermal cells of the stage 1 embryo (newly oviposited egg) can survive 3-4 weeks under conditions of cold storage $\left(8-13^{\circ} \mathrm{C}\right)$, although a low frequency of 'necrotic cells' are apparently induced under these conditions (Arora and Kosin, 1968). In nature, embryonated eggs may 
sustain considerable physical trauma and fluctuating temperature and humidity conditions, but still develop to term. In addition, blastodermal cells survive removal from eggs, culturing, and re-injection into recipient eggs, which give rise to normal chicks (Marzullo, 1970; Petitte et al, 1990; Etches et al, 1997). On the other hand, the sensitivity of blastodermal cells to widely known and studied physical and chemical stress factors has hardly been investigated, and little information is available about the regulation of stress resistance by cell death regulatory genes.

Some human cancers, arising from different cell lineages, show varying degrees of resistance to chemotherapeutic drugs (Huschtscha et al, 1995). This may be due to differential uptake or efflux of drugs mediated by the $\mathrm{P}$. glycoprotein pump, drug metabolizing enzymes, differing levels of DNA damage/repair, or differential downstream cellular responses to drug-induced damage. Our recent studies with mitomycin $\mathrm{C}$ (MMC)-induced cytotoxicity have revealed the critical importance of apoptosis as a cellular mechanism regulating drug resistance of lymphoma cells. In fact, the high resistance of T-lymphoma cells and comparative sensitivity of B-lymphoma cells to MMCinduced toxicity is due primarily to differential triggering of apoptosis (Potchinsky et al, 1995; Muscarella and Bloom, 1997). These findings suggest that processes well downstream of drug uptake, transport, metabolism, and initial molecular damage are important for regulating responses to potentially lethal damage.

Genetic studies in $C$. elegans have identified a number of genes that regulate various phases and pathways in apoptosis (Horvitz et al, 1982; Ellis and Horvitz, 1986), including ced-3 that is required for apoptosis and ced-9 that inhibits this process. At least 11 members of the Ced-3/ICE family of proteases have been identified in humans, and a number of them have been implicated in PCD. However, knowledge concerning the genetic regulation of PCD in the early vertebrate embryo is still rudimentary. Various vertebrate oncogenes are known to regulate apoptosis: c$m y c$, which promotes cell proliferation and apoptosis, is expressed at low levels in mouse oocytes and early embryos (Jurisicova et al, 1995). Bcl-2, sharing sequence and functional similarities with ced-9, has been detected as early as stage E8.5 in mouse embryos and by $E 10.5$ is prominent in the immature neural tissue of the brain and spinal cord (Novak and Korsmeyer, 1994). More recently, the bcl-2 and bax proteins were detected in sections of stage 4-5 (gastrulation) chick embryos immunostained for these antigens (Sanders et al, 1997b). Although c-myc is expressed in all proliferating cells, and promotes apoptosis under certain circumstances, its role as a potential cell death regulatory gene in pre-gastrulating embryos has not been explored.

In the present study, we have tested the hypothesis that the blastodermal cells of stage 1 (stage $X$, Eyal-Gilada and Kochav, 1976) embryos are competent to undergo apoptosis but are stress resistant by virtue of expression of genes that inhibit cell death. We examined the sensitivity of pluripotent blastodermal cells to a variety of stress factors, including temperature shock and drugs capable of triggering apoptosis within 1 to $4 \mathrm{~h}$ of exposure. Addition- ally, we examined the expression of the genes, $h s p 70, b c /-$ 2 and $b c /-x_{L}$, which are capable of inhibiting apoptotic cell death. These studies generate a picture of both the capacity of blastodermal cells to engage in apoptosis and their impressive resistance to stress-induced cell death.

\section{Results}

\section{An apoptotic mode of cell death occurs in pluripotent blastodermal cells}

Our characterization of apoptosis in stage 1 blastodermal cells was facilitated by the use of cytological squash preparations of entire blastoderms (generating a monolayer) and specific fluorescence reporting of DNA in unfixed cells using Hoechst 33342. Vitally-stained blastodermal cells from stage 1 embryos (or stage $X$ by Eyal-Giladi and Kochav, 1976) demonstrated specific blue fluorescence labeling of nuclei. Structural features detected in interphase cells included distinct chromatin network (euchromatin), heterochromatic regions, and a prominent $\mathrm{W}$-sex chromatin body in some embryos (Figure 1A). Blastodermal cells with fragmented nuclei were observed at stage 1 (newly oviposited eggs). Such cells showed stereotypic phenotypic features of apoptosis including condensed, segregated chromatin masses, loss of chromatin network, and shrunken cells (Figure 1B). Additionally and significantly, a progression of cellular changes typical of apoptosis was also observed, from accumulation of condensed chromatin near the nuclear membrane to formation of segregated chromatin masses, membrane blebs, and formation of apoptotic bodies (Figure $1 \mathrm{~B}$, see stages). We believe the apoptosis observed in the stage 1 embryos reflects normal development, since eggs were from specific-pathogen-free strains of chickens, and they were not exposed to any physical or chemical stress factors.

Blastodermal cells undergoing apoptosis were observed in stage 1 embryos (unincubated eggs) at frequencies varying from $1.0-5.5 \%$ of cells, with an average of $3.1 \%$ apoptotic for the six embryos studied. The apoptotic cells appeared to be distributed throughout the blastoderm.

\section{Temperature-shock conditions induce apoptosis in blastodermal cells}

Eggs were subjected to a cold stress that involved holding them at $12^{\circ} \mathrm{C}$ for 14 days with no turning. These conditions are typically used in both research and commercially to accumulate large numbers of eggs for incubation and hatching of groups of chicks. Interestingly, the frequency of apoptotic cells was $13.9 \pm 3.6 \%$ in these cold-stored eggs compared to $3.1 \pm 1.8 \%$ in fresh eggs (significantly different at $P<0.05)$.

Eggs that were subjected to heat-shock for $4 \mathrm{~h}$ followed by incubation for $24 \mathrm{~h}$ at $37.5^{\circ} \mathrm{C}$ showed a temperaturedependent increase in the frequency of apoptosis in blastodermal cells (Figure 2). The mean frequencies of apoptosis were not significantly increased at $45^{\circ} \mathrm{C}$ $(P>0.05)$, although two embryos exceeded controls with $5 \%$ and $6 \%$ apoptotic cells, respectively. Apoptosis was 

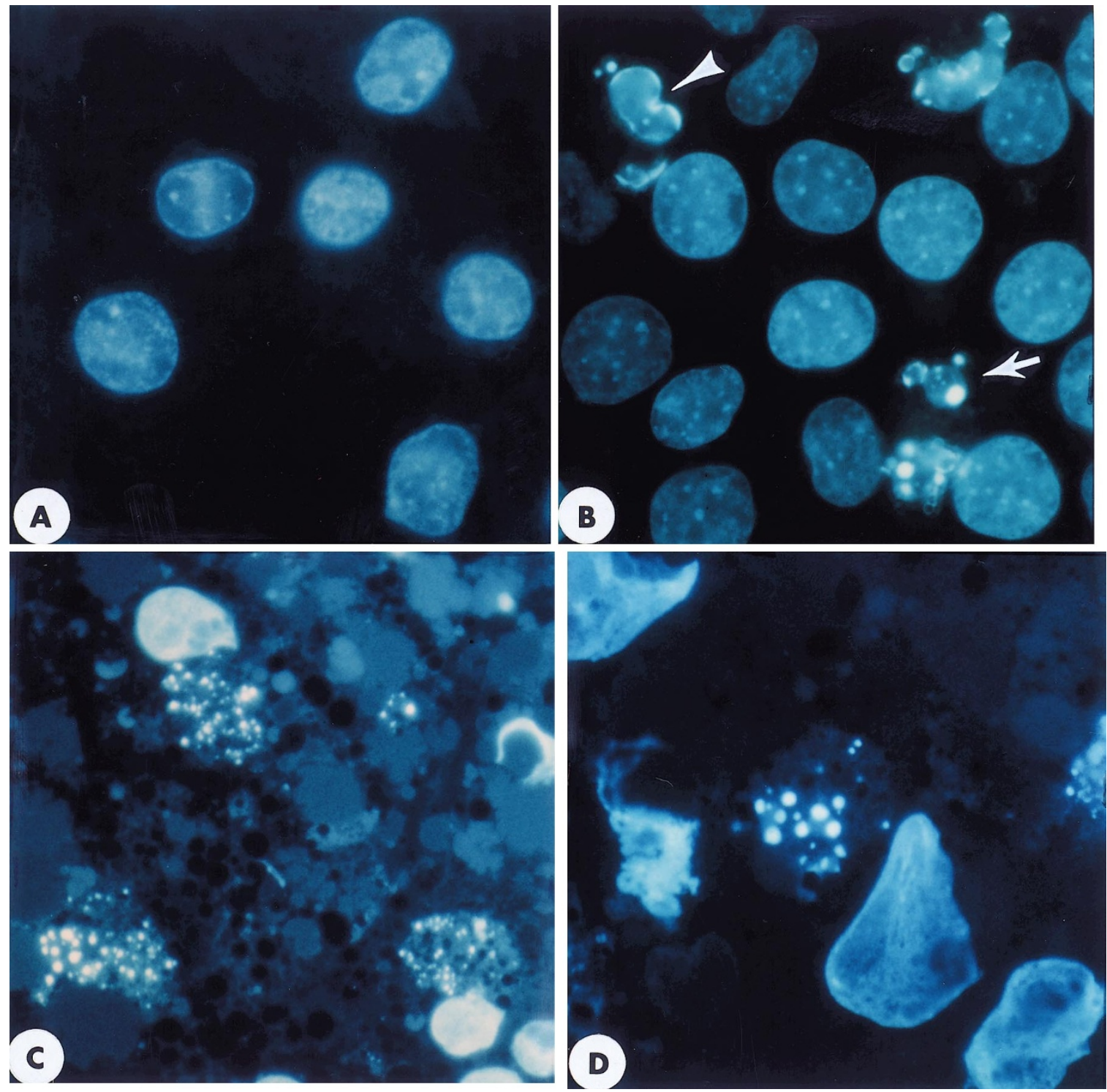

Figure 1 Spontaneous and drug-induced apoptosis in blastodermal cells. Freshly excised cells from unincubated eggs were immediately stained in Hoechst 33342 , spread to a monolayer, and viewed under epifluorescence microscopy. (A) Fluorescence of nuclei showing normal chromatin network and heterochromatin. (B) Apoptotic cells in an unincubated blastoderm. A progression of nuclear changes is seen including condensation of chromatin along the nuclear membrane (arrow head) characteristic of early apoptosis and segregation of defined chromatin masses in late apoptosis (arrow). (C) Apoptosis in blastodermal cells induced by etoposide. (D) Apoptosis induced by mitomycin C. Original magnifications are $\times 1100$ for $\mathbf{A}-\mathbf{C}$, and $\times 1600$ for $\mathbf{D}$

significantly induced at $48^{\circ} \mathrm{C}(P<0.01)$ from an average of $1.4 \%$ in controls to $10.4 \%$ in heat shocked embryos (sevenfold increase). An interesting feature of the $48^{\circ} \mathrm{C}$ heat-shock experiment was the substantial variability among embryos in the percentage of apoptotic cells, ranging from $2-70 \%$ (Figure 2 ).

\section{Blastodermal cells demonstrate features of drug resistance including delayed induction of apoptosis}

An initial screening of four drugs was performed to determine if apoptosis would be induced to a substantial degree in cell populations of the early embryo. Eggs were microinjected (beneath the blastoderm) with $5 \mu \mathrm{l}$ of $300 \mu \mathrm{M}$ MMC, $90 \mu \mathrm{M}$ STP, $100 \mu \mathrm{M}$ etoposide (ETP) and $1 \mu \mathrm{M}$ topotecan (TPT). All of these drugs are potent inducers of apoptosis in a wide variety of cell types. The concentrations used are known to induce high frequencies of apoptotic cells in mammalian and avian cell lines. Cells are known to vary considerably in resistance to killing by these drugs. Drug resistance is manifested as delayed induction of apoptosis and comparatively fewer cells engaging in apoptotic cell death. In some cases, drug resistance is due to expression of anti-apoptotic genes such as $b c l-2$. Thus, delayed and modest amounts of apoptosis in a cell population may reflect elevated expression of one or more anti-apoptotic genes and/or reduced expression of some pro-apoptotic genes. 


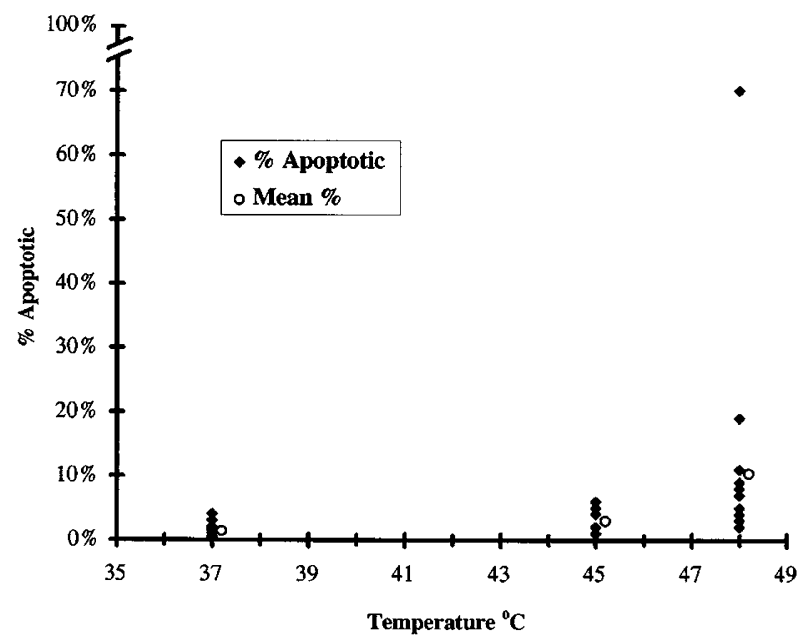

Figure 2 Induction of apoptosis in blastodermal cells in individual embryos at heat-shock temperatures of $45^{\circ} \mathrm{C}$ and $48^{\circ} \mathrm{C}$. Eggs wee heat shocked for $4 \mathrm{~h}$ and then returned to the incubator at $37^{\circ} \mathrm{C}$ for $24 \mathrm{~h}$. Apoptosis was significantly induced at $48^{\circ} \mathrm{C}(P<0.05)$

Eggs were injected and incubated for $24 \mathrm{~h}$. Apoptosis was induced with all compounds as follows: $35 \%$ with ETP, $24.3 \%$ with MMC, $19.4 \%$ with STP and $15 \%$ with TPT and $2.6 \%$ and $2.9 \%$ for the DMSO and PBS solvent controls. Additionally, there were two embryos in the MMC pilot experiment that showed $93 \%$ and $95 \%$ apoptotic cells. But, these embryos had not progressed much beyond stage 1 and may have been embryos destined to abort in the absence of drug. Nevertheless, this result is revealing about the status of the apoptotic cell death machinery in the blastodermal cell population.

MMC and ETP were selected for further study of early induction of apoptosis since they induced the highest frequencies of apoptosis. Vincristine (VCR) was added to the study since its mitotic blocking effects could be monitored by fluorescence microscopy along with the induction of apoptosis. It is also a potent inducer of apoptosis in various cell lines.

The drug ETP is known to induce apoptosis rapidly (1$4 \mathrm{~h}$ ) in various avian and mammalian cell lines. In fact, $10 \mu \mathrm{M}$ ETP induced approximately $60 \%$ and $80 \%$ apoptosis in the drug sensitive DT40 cells after 2 and $4 \mathrm{~h}$ of drug exposure, respectively (Figure 3). ETP also induced early apoptotic cell death in the drug resistant CU159 cells, but to a lesser extent (about 30\%). In contrast, ETP (10 and $100 \mu \mathrm{M}$ ) failed to induce apoptosis in blastoderm cells at $4 \mathrm{~h}$ of exposure even at high concentrations (Figure 4A). Modest induction of apoptosis was detected at $8 \mathrm{~h}$, followed by a more substantial induction at $24 \mathrm{~h}(33.4 \%$ at $100 \mu \mathrm{M})$. ETP-induced apoptotic blastodermal cells showed the stereotypic apoptotic features of condensed, segregated chromatin masses and loss of normal chromatin network (Figure 1C), as well as various stages in progression of chromatin breakdown and reorganization.

MMC induced apoptosis in the early embryo in a concentration and time-dependent manner (Figure 4B). However, the kinetics of apoptotic induction was much

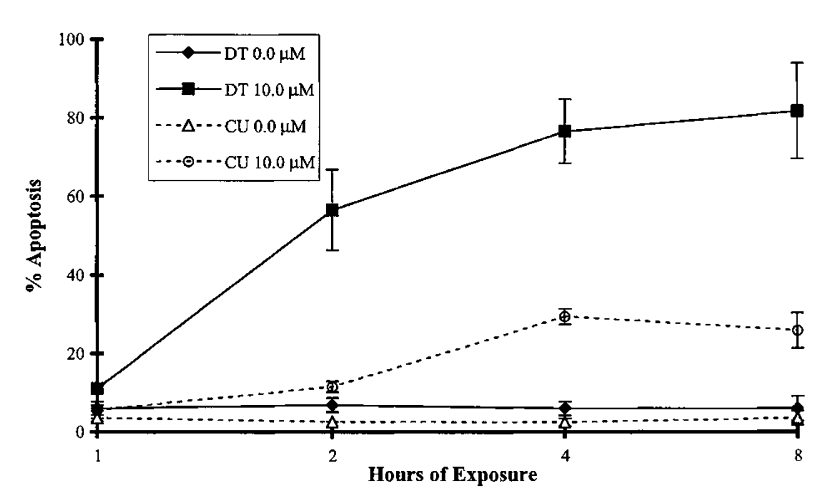

Figure 3 Comparative induction of apoptosis by etoposide in drug-resistant CU159 T-lineage lymphoma cells and drug sensitive DT40 B-lineage lymphoma cells. Apoptosis was significantly induced in DT40 cells at 2, 4 and $8 \mathrm{~h}$ compared to $1 \mathrm{~h}$; and values were significant for CU159 cells at 4 and $8 \mathrm{~h}$ compared to 1 and $2 \mathrm{~h}(P<0.05)$. ETP-treated DT40 was significantly different $(P<0.05)$ than treated CU159 at 2, 4 and $8 \mathrm{~h}$
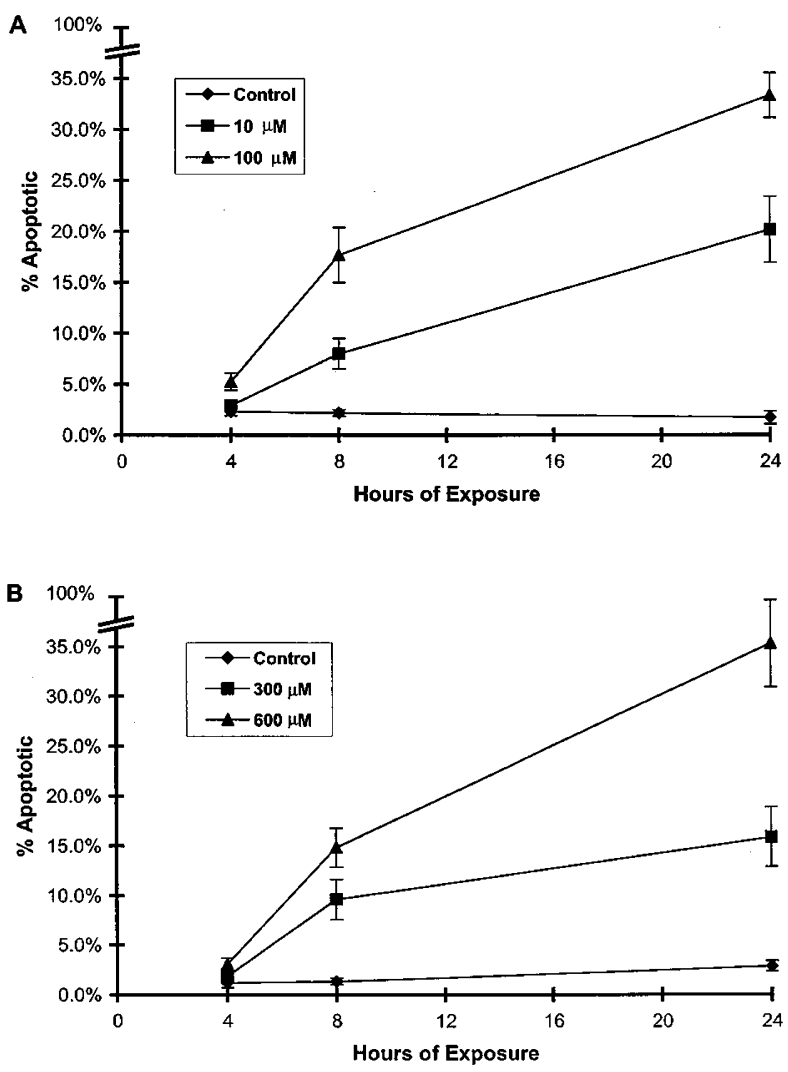

Figure 4 Time and concentration-dependent induction of apoptosis in blastodermal cells by (A) etoposide and (B) mitomycin C. Apoptosis was significantly induced only at 8 and $24 \mathrm{~h}$ for both drugs $(P<0.05)$. Drug induction of apoptosis did not exceed $35 \%$ and was delayed when compared to the DT40 and CU159 cells lines

slower than that observed in other cell types including tumor cell lines. Apoptosis was not induced by MMC at $4 \mathrm{~h}$ post exposure. A modest increase in apoptosis was seen at 
$8 \mathrm{~h}$, but substantially more apoptosis was induced by $24 \mathrm{~h}$ $(35.3 \%$ at $600 \mu \mathrm{M})$.

ETP and MMC treated embryos incubated for $24 \mathrm{~h}$ failed to undergo normal gastrulation and appeared to be inhibited between stages 2 and 3 . This is not surprising since these drugs can inhibit cell cycle progression, induce changes in gene expression, and induce cell death.

The drug VCR, unlike the other drugs, binds to tubulin and induces a mitotic block (C-metaphase) in proliferating cells. After just $4 \mathrm{~h}$ of exposure to VCR, about $15 \%$ of blastodermal cells were blocked in mitosis (Figure 5A). The frequency of blocked cells continued to increase at $8 \mathrm{~h}$, with a maximum of $28.5 \%$ at the highest concentration of VCR. The percentage of blocked mitotic cells declined by $24 \mathrm{~h}$. Concomitant with this decrease in mitotic cells was a substantial increase in apoptotic cells from a low of $4.6 \%$ at $8 \mathrm{~h}$ to a maximum of $32.3 \%$ at $24 \mathrm{~h}$ (Figure 5B).

\section{Anti-apoptotic genes are expressed in blastodermal cells and show a developmental pattern of expression}

We used RT-PCR to determine whether transcripts from selected genes known to play a role in inhibiting apoptosis are
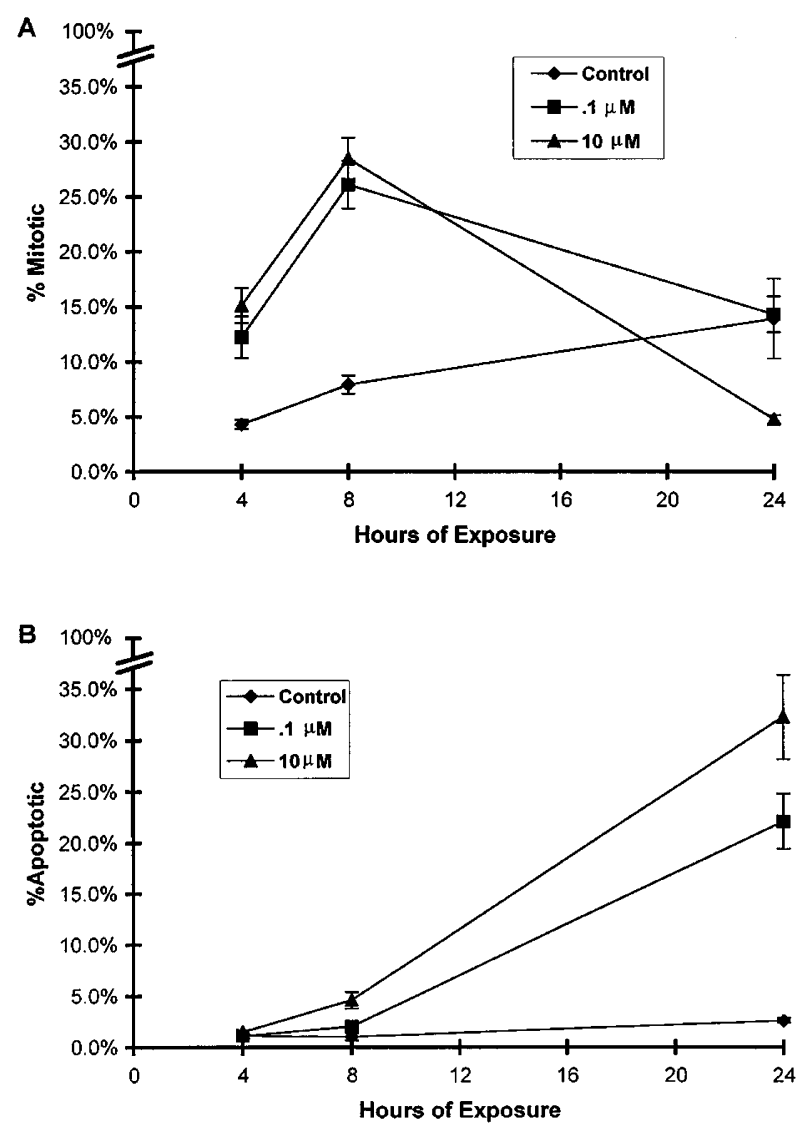

Figure 5 Time-dependent accumulation of vincristine-blocked (A) mitotic blastodermal cells and (B) apoptotic blastodermal cells. Percent mitotic cells was significantly increased at 4 and $8 \mathrm{~h}$ compared to controls $(P<0.05)$. Apoptosis was significantly induced at $24 \mathrm{~h}(P<0.05)$ expressed in the blastodermal and early embryonic cells. Figure 6 shows the results of RT-PCR detection of RNA transcripts for $b c /-2$ (lanes 1, 5, 9, 13), constitutive expression of $h s p 70$ (lanes 2, 6, 10, 14), bcl- $x_{L}$ (lanes 3, 7, 11, 15), and $\beta$ actin (lanes $4,8,12,16$ ) in the stage 1 (newly oviposited) embryo (lanes 1-4), stage 2 (4 h) embryo (lanes 5-8), stage $4(20 \mathrm{~h}$ ) embryo (lanes $9-12)$ and 14 day of incubation liver (lanes 13-16).

Embryonic cells at stages 1, 2, and 4 expressed, at least to some extent, all three anti-apoptotic genes. Although the RT-PCR experiment shown here was optimized for the detection of potentially low abundance transcripts, and therefore is only semi-quantitative, differences in gene expression were revealed. We consistently obtained strong signals for $h s p 70$ and $\beta$-actin, at the three stages of embryonic development, suggesting the relative abundance of these transcripts. Hsp70 appears to be constitutively expressed in the early embryo, as well as in some tissues at later developmental stages. However, for other tissues such as thymus from 1 week old birds, we found that constitutive levels of $h s p 70$ were minimal relative to the transcript levels for other genes (data not shown).

$\mathrm{Bcl}-2$ message was detected at all three stages of embryonic development. A relatively weak signal was obtained at stage 1, but a stronger signal was consistently found at later developmental stages (Figure 6). In contrast, $b c l-x_{L}$ transcripts were not detected at stage 1 in this experiment, and only a very weak signal was observed at the other embryonic stages. In contrast, embryonic liver showed a strong signal for $b c /-x_{L}$. The finding of comparatively low expression of $b c l-x_{L}$ in the early embryonic samples is reproducible among experiments. These results suggest that the $b c l-x_{L}$ transcript is of low abundance in the early embryo, and therefore, at the lower limit of detection.

The results of the RT-PCR experiments were consistent for several independent embryonic samples with the following exception: some sample to sample variability for $b c l-2$ and $b c l-x_{L}$ transcripts was detected for stage 1 embryos. Specifically, in contrast to the experiment illustrated here, a strong signal for $b c /-2$ was detected in some stage 1 samples, and some samples were also positive for $b c /-x_{L}$ at stage 1 , although the signal for this gene transcript was always weak. This suggests that the expression of certain genes may vary among stage 1 embryos, but this variability decreases at later develop-

$\begin{array}{llllllllllllllll}1 & 2 & 3 & 4 & 5 & 6 & 7 & 8 & 9 & 10 & 11 & 12 & 13 & 14 & 15 & 16\end{array}$

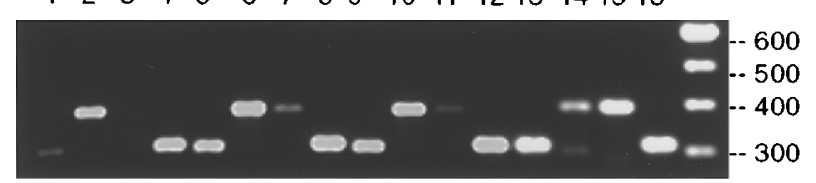

|-- stage 1 ..-||---stage 2---||--stage 4-..-||--.----|v-...-.--|

Figure 6 Expression of cell death regulatory genes in the early embryo. RT PCR detection of messages for $b c l-2$, lanes 1, 5, 9, 13; $h s p 70$, lanes 2, 6, 10, $14 ; b c l-x_{L}$, lanes $3,7,11,15$; and $\beta$-actin, lanes $4,8,12,16$. Reactions were performed with RNA samples collected at embryonic stages 1, 2, 4 and 14 day of incubation liver (Iv) 
mental stages. We cannot exclude the possibility that the observed variability is due to differences in the amount of total RNA isolated at this stage of development, which is a reflection of the small number (approximately $30000-$ 50000 ) of cells present in the blastoderm. However, signals for $h s p 70$ and $\beta$-actin were consistently strong at all embryonic stages including stage 1 , and no variation was seen for any of the genes studied among stage 2 samples which, like stage 1 samples, also had relatively low cell numbers.

\section{Discussion}

\section{Programmed cell death in the chick blastoderm}

The health of the early embryo may be threatened by exposure to environmental stress factors and the de novo generation of genetic aberrations involving gene mutation, non-disjunction of chromosomes, and aberrant gene expression. Evidence is accumulating that the early vertebrate embryo (i.e. cleavage states through blastula) is relatively stress resistant. The mechanism for this resistance is not the lack of expression of a cell death program, since apoptosis can be induced by drugs in a high percentage of blastomeres in mouse embryos (Weil et al, 1996), and in the present study we observed two embryos arrested at about stage 1 with over $90 \%$ apoptotic cells. Therefore, the evidence to date supports the hypothesis that early embryonic cells are protected against stress-induced cell death. However, there are only fragmentary data to support this hypothesis and there are technical challenges to studying this aspect in early stages of development.

The early expression of a cell death program may well function as a mechanism to eliminate aberrant cells and regulate cell numbers. In the mammalian blastocyst, some inner cell mass cells with the potential to form trophoectoderm die by apoptosis, and this may represent a mechanism for eliminating redundant cells (Pierce et al, 1989). It would seem hazardous for early embryo cells to have a suicide capacity, but this may be counteracted by the expression of one or more anti-apoptotic regulatory genes and cytoprotective systems. Our study was conducted to explore both the question of the presence of a cell death program in pluripotent blastodermal cells and the potential resistance of these cells to stress-induced apoptosis. We also examined the expression of genes that may play a prominent role in regulating stress resistance in the early embryo.

Our studies provide substantial evidence for the occurrence of apoptosis in the unincubated stage 1 blastoderm (Stage X, Elyal-Giladi and Kochav, 1976). This was facilitated by the utilization of squash preparations of entire blastoderms (generating a monolayer of cells), vital staining with the DNA-specific fluorochrome Hoechst 33342, and extensive observational experience in detecting apoptosis in normal and transformed cells (Potchinsky et al, 1995; Hemendigner and Bloom, 1996; Muscarella and Bloom, 1997). We were able to observe the various stages of both nuclear and cytoplasmic changes that characterize apoptotic cell death. Apoptotic cell phenotypes in the early embryo were very similar to those described in many other cell types. We detected a low frequency of apoptotic blastodermal cells $(3.1 \%)$, which is similar to the level of about $2.0 \%$ reported by Arora and Kosin (1968). It is likely that the 'necrotic cells' that these investigators observed in tissue sections were apoptotic, since they detected fragmented nuclei using the Feulgen stain. This low frequency of apoptosis could potentially delete 1000 or more cells in an individual blastoderm. We were not able to localize the cell deaths with precision, but they appeared to be scattered throughout the blastoderm. This suggests that early deaths delete aberrant and redundant cells. A variety of cytogenetic abnormalities in the early chick embryo have been observed previously including aneuploidy, haploidy, and polyploidy (Bloom, 1972). Also, many embryos are mosaics and chimeras (Fechheimer et al, 1983; Bloom, 1972). Such embryos are usually arrested in early development, and perhaps this is due to excessive cell deaths. However, many abnormal embryos are karyotypically normal, and these embryos may be aberrant in other respects, perhaps in the altered expression of cell-death related genes.

\section{Blastodermal cells demonstrate resistance to temperature shocks}

Heat and cold shocks represent real-world potential stresses for the avian embryo. Additionally, previous work suggests that temperature variations may induce abnormal or arrested development (Arora and Kosin, 1968; Romanoff, 1972). Prolonged cold storage of chicken eggs, beyond 2 weeks, reduces the viability of embryos upon incubation. We found that the storage of eggs under the typical holding temperature of $12^{\circ} \mathrm{C}$ for 14 days resulted in an increase in the frequency of apoptotic blastodermal cells. This in agreeement with the observations of increased 'necrosis' in cold stored eggs previously reported (Arora and Kosin, 1968). These observations suggest that at least some components of the apoptotic cell death cascade are functional at low temperatures. Additionally, the frequency of mitotic cells has also been reported to increase (presumably by inhibition in M-phase) with storage at $12^{\circ} \mathrm{C}$ but not at $7^{\circ} \mathrm{C}$, further demonstrating some physiological activity of cells at $12^{\circ} \mathrm{C}$ (Arora and Kosin, 1968). These findings show the hardiness of the blastodermal cells to longterm holding in the cold, but at the same time suggest that relatively modest amounts of cell death $(6-14 \%$ of cells) can influence the subsequent viability of embryos.

Resistance to heat-shock conditions was demonstrated by the lack of induction of apoptosis at $45^{\circ} \mathrm{C}$ and the modest induction $(10 \%)$ at the higher temperature of $48^{\circ} \mathrm{C}$. However, heat resistance was variable among the embryos. This may be due to variable expression of cell death genes or to variable developmental status of embryos at the commencement of heat shock. Other studies of heat shock showed that the heat shock proteins are inducible in avian blastodermal cells, although the degree of variability in this induction is not known (Zagris and Matthopoulos, 1986). 


\section{Blastodermal cells display a drug resistant phenotype and may be protected by several cell death regulatory genes}

Our tests of the microinjection procedure revealed accurate targeting of drug solutions to the blastoderm and rapid uptake into blastodermal cells. For example, all blastodermal cells demonstrated blue fluorescence in nuclei after just 15 min following microinjection of Hoechst 33342. This indicated rapid uptake, intracellular movement, and binding of the dye to DNA.

Chick blastodermal cells demonstrated resistance to drug-induced apoptosis. This was demonstrated by both the delayed induction and the relatively low frequencies of apoptotic cells, about $35 \%$ after $24 \mathrm{~h}$ of exposure even at the high drug concentrations. This compares with about $80 \%$ apoptosis induced at $4 \mathrm{~h}$ in the DT40 cell line, which is known to be sensitive to the induction of apoptosis by many drugs (Potchinsky et al, 1995; Muscarella and Bloom, 1997). In addition, drug-induced apoptosis in blastodermal cells is delayed even compared to the multi-drug resistant CU159 cells, which show some apoptosis by $4 \mathrm{~h}$ of drug exposure. Apoptotic responses in CU159 and blastodermal cells were similar in that a maximum of about $30 \%$ apoptosis was induced by drug treatment. Such cell resistance may reflect low expression of pro-apoptotic genes such as the caspases or oncogenes such as c$m y c$, or high expression of anti-apoptotic genes such as $b c /-2$, or both conditions may exist in cells. Studies with cleavage stage mouse embryos revealed resistance of 2-4 cell-stage embryos to STP-induced apoptosis. Blastomeres were resistant to $1 \mu \mathrm{M}$ STP. Apoptosis was induced at a tenfold higher STP concentration only after 36-60 h of exposure (Weil et al, 1996). Apoptosis was also induced in a delayed manner with STP and the other drugs in the chick blastoderm. These studies suggest that early cleavage cells are generally resistant to cell killing by drugs and environmental stresses.

We detected transcripts for three genes in the early chick embryo that have the capacity to antagonize druginduced apoptosis: $b c l-2, b c l-x_{L}$, and $h s p 70$. The presence of these anti-apoptotic gene messages correlates with the observed delayed and limited induction of apoptotic cell death in the early embryo. Additional studies are needed to determine the specific contributions of these and other cell regulatory genes in determining the resistance of blastodermal cells to apoptosis induction.

$\mathrm{Bcl}-2$, part of a larger gene family, protects a wide variety of cells against apoptosis induced by different stimuli. Although the mechanisms of protection against apoptosis by $b c /-2$ are not fully understood, it apparently plays a role in the regulation of pore opening of mitochondria (Zamzami et al, 1996), and in protection against oxidative damage (Hockenbery et al, 1993). Using immunohistochemistry, Sanders et al. (1997b) found that $b c l-2$ was distributed throughout the gastrulating (stage 4) chick embryo. In the present study, we found that $b c l-2$ is expressed at earlier developmental stages as well.

Other members of the $b c l$ gene family, such as $b c l-x_{L}$, also confer protection at least against some forms of apoptosis induction (Boise et al, 1993). $B c /-x_{L}$ is expressed in a variety of adult and embryonic tissues (Boise et al, 1993; Vilagrasa et al, 1997). Our analysis of $b c /-x_{L}$ transcripts showed that this gene is expressed in the avian pre-streak and gastrulating embryo. However, with the exception of embryonic liver, a relatively low signal for $b c l-x_{L}$ was detected compared to $b c l-2$. This suggests that the $b c l-x_{L}$ gene product is present at low levels in the early embryo. Therefore, $b c l-2$ is likely to play a more significant role in regulating the induction of apoptosis.

Unlike other vertebrates, the chicken has a single $h s p 70$ gene (Morimoto et al, 1986). We found that the gene for hsp70 is constitutively expressed in the early avian embryo. Hsp70 protein has been shown to protect tumor cells against apoptosis induction (Samali and Cotter, 1996; Wei et al, 1995). This protective effect appears to be mediated at multiple levels, by blocking early signaling events in the stress activated protein kinase signaling pathway, and by directly or indirectly blocking the activation of caspase 3 or other proteases involved in executing the apoptotic cascade (Mosser et al, 1997). High levels of hsp70 expression have been found upon activation of the embryonic genome in mouse and other species (Bensaude et al, 1983; Christians et al, 1995). The expression of $h s p 70$ at these embryonic stages is independent of stress-induction. Our consistent detection of a strong signal for $h s p 70$ in blastodermal cells indicates that the early avian embryo also has a high constitutive level of hsp70 mRNA, and suggests that the expression of this gene may contribute to the relative resistance of these cells to stressinduced apoptosis.

Like other members of the heat shock family of proteins, expression of $h s p 70$ is induced upon exposure of cells to a variety of forms of stress. Consequently, hsp70 mRNA and protein are typically not observed in non-stressed cells by blotting analysis. However, the sensitivity of RT-PCR techniques indicates that some level of hsp70 transcript is constitutively present in at least some cell types (Mivechi and Rossi, 1990).

Our determination that the early avian embryo is relatively resistant to the induction of apoptosis by heat shock supports the hypothesis that high levels of hsp70 are protective for the early embryo. However, evidence also indicates that avian blastodermal cells are capable of an inducible heat shock response as well (Zagris and Matthopoulos, 1986). To what extent constitutive expression versus induction of hsp70 may contribute to protection from drug-induced apoptosis induction is unknown. While some chemotherapuetic drugs are capable of inducing expression of the heat shock proteins, others do not (Schaefer et al, 1988). If one role of hsp70 involves protection against various forms of stress in the early embryo, constitutive levels as well as inducible levels of hsp70 may provide an important protective role against apoptosis induced by chemical agents.

The findings of our study reveal (1) the capacity of pluripotent blastodermal cells to engage in an apoptotic mode of cell death, and (2) their high resistance to temperature stress and potent cytotoxic drugs. This latter property may be due to the high constitutive expression of 
the anti-apoptotic gene $h s p 70$, but also due to contributions from multiple cell death genes and other cytoprotective systems. These studies with the chick embryo provide the foundation for future investigation of the regulation of cell death in early embryonic stages, and offers an in vivo system to investigate the modulation of resistance or susceptibility to specific drugs and stress factors.

\section{Materials and Methods}

\section{Animals and embryos}

Fertile eggs were obtained from specific-pathogen-free Cornell P-line chickens. The eggs were brought to the lab for studies within $1-3 \mathrm{~h}$ of oviposition. Most embryos were diagnosed to be at stage $X$ (EyalGiladi and Kochav, 1976; Delany et al, 1995). Manipulations were performed on eggs containing the stage $X$ embryos. The eggs were subsequently incubated for various durations at $37.5^{\circ} \mathrm{C}$ in a humidified chamber and rotated once/h. Developing embryos were staged using the Hamburger and Hamilton $(\mathrm{HH})(1951)$ classification system. For consistency in designating stages in the present study, we have used $\mathrm{HH}$ stage 1 to indicate the equivalent of stage $X$ of Eyal-Giladi and Kochav (1976). In experiments, 10-14 embryos were analyzed for each treatment and timepoint.

\section{Temperature shock}

Fresh eggs were cold shocked by storing at $12{ }^{\circ} \mathrm{C}$ and $50 \%$ humidity for a duration of 14 days. Heat shock was performed on groups of eggs in a model 3M oven as follows: Experimental eggs were incubated for $1 \mathrm{~h}$ at $37.5^{\circ} \mathrm{C}$, then exposed to either $45^{\circ} \mathrm{C}$ or $48^{\circ} \mathrm{C}$ for $4 \mathrm{~h}$, and then returned to $37.5^{\circ} \mathrm{C}$ for $24 \mathrm{~h}$. Control eggs were incubated at $37.5^{\circ} \mathrm{C}$ for the total time of $29 \mathrm{~h}$.

\section{Drug exposures}

Five drugs were used to induce apoptosis in embryos. These include the potent drugs ETP and TPT that typically induce apoptosis in tumor cell lines within 2-4 h. STP inducing apoptosis in 4-8 h; and MMC and vincristine VCR inducing apoptosis in 8-12 $\mathrm{h}$. The solvent for ETP and STP was DMSO and 5\% dextrose and water for TPT and MMC, respectively. These drugs also induce different types of initial damage in cells including inhibition of topoisomerases (ETP, TPT), induction of DNA damage (MMC), inhibition of protein kinases (STP), and binding to tubulin (VCR).

Windows were made in sides of eggs to expose the blastoderm. Drugs were micro-injected with a $5 \mu$ l capacity Hamilton glass syringe just beneath the blastoderm. The window was then sealed with a small piece of saran wrap, and egg albumin used as a sealant. After $1 \mathrm{~h}$ of incubation on their sides, eggs were returned to the vertical position for continued incubation.

The success of targeting the microinjections and optimal amounts of solutions to expose all blastodermal cells were determined using Hoechst 33342, a fluorescent dye that penetrates viable and non-viable cells and binds specifically to DNA. The Hoechst-DNA complex is easily visualized by its intense blue fluorescence. Varying amounts of Hoechst 33342 were injected beneath the blastoderm, and then eggs were either examined immediately, or some were incubated first and then examined at 15 min intervals for dye uptake and binding in cell nuclei with a Leitz Aristoplan epifluorescence microscope system. Significantly, all cells in blastodermal cytological preparations showed Hoechst 33342-specific fluorescence of nuclei after just 15 min post-injection.

\section{Embryo excision and cytological preparations}

Embryos at 4, 8, 12 and $24 \mathrm{~h}$ (HH stages $1+, 2+, 3,6-7$, respectively) were removed from eggs by making an incision in the vitelline membrane with a microscalpel next to the embryo and then inserting a microcapillary tube $(I D=1.1 \mathrm{~mm})$ fitted with a small rubber bulb. The tip of the tube was positioned just adjacent to the embryo, which was taken up into the tube by negative pressure. The embryo was then expelled onto a clean microscope slide for subsequent examination, dissection, and staining. $\mathrm{HH}$ stage $12-13$ embryos (48 $\mathrm{h}$ of incubation) were removed from eggs using filter paper rings followed by dissection of the embryo from the surrounding membrane. For gene expression studies the excised embryos were processed as described below for RNA isolation.

\section{Cell lines for comparative studies of apoptosis induction}

The DT40 B-lymphoma and CU159 T-lymphoma cell lines were used to study and compare the kinetics of etoposide induction of apoptosis with embryonic cells. We have shown previously that DT40 cells are sensitive and CU159 cells resistant to the cytotoxic effects several chemotherapeutic drugs (Potchinsky et al, 1995). Additionally, the basis for the difference in resistance of these cell lines to MMC and camptothecin is differential triggering of apoptosis and not differential drug uptake or DNA damage and repair (Muscarella and Bloom, 1997). The cell lines were exposed to $10 \mu \mathrm{M}$ etoposide for $1,2,4$ and $8 \mathrm{~h}$ and assessed for apoptosis induction at these timepoints. Replicate experiments were performed with the cell lines.

\section{Assay for apoptosis and fluorescence detection}

Embryonic cells were prepared for detection of apoptosis by modification of a method we previously developed for lymphoma cell lines (Potchinsky et al, 1995). Briefly, newly excised blastoderms or embryos were stained in $30 \mu \mathrm{l}$ of $100 \mu \mathrm{g} / \mathrm{ml}$ Hoechst 33342 on the microscope slide for $15 \mathrm{~min}$, at room temperature, and under low light conditions. The slide was then gently mounted with a $22 \times 40 \mathrm{~mm}$ cover slip. The preparation was pressed by moderate thumb pressure in a bibulous paper book, taking care to avoid lateral slippage of the coverslip. This procedure produces a monolayer of the blastoderm or early embryo, facilitating the quantitation of apoptosis in the cell population. The DNA-specific fluorescence of Hoechst 33342 in nuclei (vitally stained) was observed using a Leitz Aristoplan microscope equipped for epifluorescence, with long-pass filter cube $A$ in the light path, and equipped with an Orthomat $E$ automatic camera for recording images on color film. Cells were classified as apoptotic by strict morphologic criteria including the presence of multiple, condensed and segregated chromatin bodies (apoptotic nuclear bodies), uniform bright fluorescence within apoptotic nuclear bodies, concurrent loss of diffuse chromatin network characteristic of normal nuclei, shrunken cytoplasm, and formation of apoptotic bodies. We also looked for evidence of a progression of cellular changes expected to occur in the execution phase of apoptosis. The percentage of apoptotic cells was determined for each slide preparation.

\section{RNA isolation from embryonic samples}

Total embryonic RNA was isolated using the GlassMAX RNA Microisolation Spin Cartridge System (Life Technologies). Blastoderms and early embryos were removed as described above and immediately immersed in ice-cold guanidine isothiocyanate/2mercaptoethanol solution. Embryos from four eggs were pooled for 
Table 1 PCR primer sequences and expected fragment sizes

\begin{tabular}{lcc}
\hline & Upstream & Fragment \\
Gene & primer & Downstream \\
bcl-2 & TACCTGCTTACACTTAGGAAGG & primer \\
bcl-x & (base pairs) & 307 \\
hsp70 & TGGTGGAGTGATGACTGC & ATCTCCTTGTCCACG \\
actin & CACCCCTGTGATGAAACA & CCTATCTCTGTTGGCTTCATCC \\
\hline
\end{tabular}

${ }^{1}$ Sequences shown as 5'-3'; references for sequence information: bcl-2, Cazals-Hatem et al, 1992; Eguchi et al, 1992; bcl-X Vilagrasa et al, 1997; hsp 70, Morimoto et al, 1986; actin, Kost et al, 1983

the stage 1 and 2 samples, and two embryos pooled at stage 4. Based on literature values of cell numbers in oviposited chicken eggs (EyalGiladi and Kochav, 1976; Petitte et al, 1990) we estimate 1.5$2.5 \times 10^{5}$ cells per pooled sample.

RNA was purified using the GlassMax columns following the manufacturer's directions, and eluted in a final volume of $40 \mu \mathrm{l}$ diethylpyrocarbonate (DEPC)-treated water. Following purification, the RNA was treated with DNase I in order to remove any contaminating DNA. Five units of DNase I, amplification-grade (Life Technologies), was added to each sample along with $5 \mu$ of the provided $10 \times$ buffer. Samples were incubated for $15 \mathrm{~min}$ at room temperature. $5 \mu \mathrm{l}$ of $25 \mathrm{mM}$ EDTA was then added to each sample, which was then incubated at $65^{\circ} \mathrm{C}$ in order to destroy the DNase I activity.

Total RNA from embryonic liver was purified using TRIzol Reagent (Life Technologies) as follows: $50 \mathrm{mg}$ of tissue was homogenized in $1 \mathrm{ml}$ of TRIzol reagent. Samples were processed following manufacturer's directions. An aliquot of approximately $1 \mu \mathrm{g}$ of RNA was diluted into $40 \mu \mathrm{l}$ of DEPC-water and treated with DNase I as described above. All samples were subjected to RT-PCR using the primers described below and $18 \mathrm{~S}$ ribosomal RNA primers (Ambion), in the presence or absence of reverse transcriptase to insure that no DNA contamination of the RNA samples occurred.

\section{RT - PCR detection of embryonic transcripts}

Primers used for the RT - PCR reactions, and the expected size of the amplification products are summarized in Table 1. All PCR products were subjected to diagnostic digests with at least two restriction enzymes to confirm the identity of the amplication products.

RT-PCR reactions were performed using the Perkin Elmer GeneAmp RNA-PCR kit. $3 \mu$ l of sample RNA was reverse transcribed in $1 \times$ reaction buffer $\left(5 \mathrm{mM} \mathrm{MgCl}_{2}, 1 \mathrm{mM}\right.$ each dGTP, dATP, dCTP and dTTP, $2.5 \mu \mathrm{M}$ random hexamers, $1 \mathrm{U} / \mu \mathrm{l}$ RNase inhibitor) containing $2.5 \mathrm{U} / \mu \mathrm{l}$ MuLV reverse transcriptase in a total reaction volume of $20 \mu \mathrm{l}$. Reverse transcriptase was omitted for RTcontrol reactions for each sample (data not shown). Reactions were incubated at room temperature for $10 \mathrm{~min}, 42^{\circ} \mathrm{C}$ for $15 \mathrm{~min}$, and then heated to $99^{\circ} \mathrm{C}$ for $5 \mathrm{~min}$ and cooled to $4^{\circ} \mathrm{C} .5 \mu$ aliquots were used for PCR reactions in a total volume of $25 \mu$, containing AmpliTaq DNA polymerase (Perkin Elmer) at $0.025 \mathrm{U} / \mu \mathrm{l}$ in $1 \times \mathrm{PCR}$ buffer II, $0.15 \mu \mathrm{M}$ each of the specific primers, and with the addition of $\mathrm{MgCl}_{2}$ to a final concentration of $2 \mathrm{mM}$. Samples were denatured at $95^{\circ} \mathrm{C}$ for $5 \mathrm{~min}$, followed by 40 cycles at $95^{\circ} \mathrm{C}$ for $60 \mathrm{~s}, 60^{\circ} \mathrm{C}$ for $60 \mathrm{~s}, 75^{\circ} \mathrm{C}$ for $90 \mathrm{~s}$ and a final extension of $72^{\circ} \mathrm{C}$ for $5 \mathrm{~min}$ in an MJ PTC-150 minicycler (MJ Research Inc.). An aliquot of each reaction $(12 \mu \mathrm{l})$ was electrophoresed in $1.5 \%$ agarose gel, stained with ethidium bromide, and visualized using an Alpha Imager 2000 Documentation and Analysis System, equipped with AlphaEase version 3.2 software (Alpha Innotech Corp.) for molecular weight determination of the amplified fragments and products of the restriction digests.

\section{Statistical analysis}

Statistical analysis with respect to the induction of apoptosis was performed using a one-way analysis of variance (ANOVA) followed by post-hoc testing with Fisher's Protected Least Significance Difference test. The alpha level for significance was set at $P<0.05$.

\section{Acknowledgements}

The authors thank Drs Esmond Sanders and Murray Bakst for stimulating and helpful discussions. This research was supported by a USDA NRI grant (9603170).

\section{References}

Arora KL and Kosin IL (1968) The response of the early chicken embryo to preincubation temperature as evidenced from its gross morphology and mitotic pattern. Physiol. Zool. 41: 104-113

Bellairs R (1961) Cell death in chick embryos as studied by electron microscopy. J. Anatomy 95: 54-63

Bensaude O, Babinet C, Morange M and Jacob F (1983) Heat shock proteins, first major products of zygotic gene activity in the mouse embryo. Nature 305: 331 333

Bloom SE (1972) Chromosome abnormalities in chicken embryos: types, frequencies, and phenotypic effects. Chromosoma 37: 309-326

Boise LH, Gonzalez-Garcia M, Postema CE, Ding L, Lindsten T, Turka LA, Mao X, Nunez $\mathrm{G}$ and Thompson CB (1993) Bcl-X, a bcl-2-related gene that functions as a dominant regulator of apoptotic cell death. Cell 74: 597-608

Cazals-Hatam DL, Louie DC, Tanka S and Reed JC (1992) Molecular cloning and DNA sequence analysis of cDNA chicken homologues of $\mathrm{Bcl}-2$ oncoprotein. Biochem. Biophys. Acta. 1132: 109-113

Christians E, Campion E, Thompson EM and Renard J-P (1995) Expression of the HSP70.1 gene, a landmark of early zygotic activity in the mouse embryo, is restricted to the first burst of transcription. Development 121: 113-122

Delany ME, Taylor RL and Bloom SE (1995) Teratogenic development in chicken embryos associated with a major deletion in the rRNA gene cluster. Dev. Growth Different. 37: 403-412

Eguchi Y, Ewert DL and Tsujimoto Y (1992) Isolation and characterization of the chicken bcl-2 gene: expression in a variety of tissues including lymphoid and neuronal organs in adult and embryo. Nucl. Acids Res. 20: 4187-4192

Ellis RR and Horvitz HR (1986) Genetic control of programmed cell death in the nematode C. elegans. Cell 44: 817-829

Etches RJ, Clark ME, Zajchowski L, Speksnijder G, Verrinder Gibbins AM, Kino K, Pain B and Samaru J (1997) Manipulation of blastodermal cells. Poultry Sci. 76: 1075-1083

Eyal-Giladi H and Kochav S (1976) From cleavage to primitive streak formation: a complementary normal table and a new look at the first stages of the development of the chick. I. General morphology. Dev. Biol. 49: 321-337

Fechheimer NS, Isakova GK and Belyaev DK (1983) Mechanisms involved in the spontaneous occurrence of diploid-triploid chimerism in the mink ( $M$. vison) and chicken (G. domesticus). Cytogenet. Cell Genet. 35: 238-243

Glucksmann A (1951) Cell deaths in normal vertebrate ontogeny. Biol. Rev. 26: 59 86 
HamburgerV and Hamilton HL (1951) A series of normal stages in the developmento the chick embryo. J. Morph. 88: 49-92

Hemendinger RA and Bloom SE (1996) Selective mitomycin C and cyclophosphamide induction of apoptosis in differentiating B lymphocytes compared to $T$ lymphocytes in vivo. Immunopharm. 35: 71-82

Hockenbery DM, Oltvai ZN, Yin X-M, Milliman CL and Korsmeyer SJ (1993) Bcl-2 functions in an antioxidant pathway to prevent apoptosis. Cell 75: 241-251

Horvitz H, Ellis $\mathrm{H}$ and Stemberg $\mathrm{P}$ (1982) Programmed cell death in nematode development. Neurosci. Comment. 1: 56-65

Huschtscha LI, Bartier WA, Malmstrom A and Tattersall HN (1995) Cell death by apoptosis following anticancer drug treatment in vitro. Internat. J. Oncology 6 : 585-593

Jacobsen MD, Weil M and Raff MC (1997) Programmed cell death in animal development. Cell 88: $347-354$

Jacobsen W (1938) The early development of the avian embryo. J. Morph. 62: 445501

Jurisicova A, Varmuza S, Casper RF (1995) Involvement of programmed cell death in preimplantation embryo demise. Human Repro. Update 1: 558-566

Kost TA, Theodorakis N and Hughes SH (1983) The nucleotide sequence of the chick $\beta$-actin gene. Nucleic Acids Res. 1123: 8287-8301

Marzullo G (1970) Production of chick chimaeras. Nature, Lond. 225: 72-73

Mivechi N and Rossi JJ (1990) Use of polymerase chain reaction to detect the expression of the $\mathrm{Mr} 70,000$ heat shock genes in control or heat shock leukemic cells as correlated to their heat response. Cancer Res. 50: 2877-2884

Morimoto RI, Hunt C, Huang S-Y, Lee Berg K and Banerji SS (1986) Organization, nucleotide sequence, and transcription of the chicken HSP70 gene. J. Biol. Chem. 261: $12692-12699$

Mosser DD, Caron AW, Bourget L, Denis-Larose C and Massie B (1997) Role of the human heat shock protein hsp70 in protection against stress-induced apoptosis. Mol. Cell. Biol. 17: 5317-5327

Muscarella DE and Bloom SE (1997) Involvement of gene-specific DNA damage and apoptosis in the differential toxicity of mitomycin $\mathrm{C}$ analogs towards B-lineage versus T-lineage lymphoma cells. Biochem. Pharm. 53: 811-822

Novack DV and Korsmeyer SJ (1994) Bcl-2 protein expression during murine development. Am. J. Pathol. 145:61-73
Petitte NJ, Clark ME, Liu G, Verrinder Gibbins AMand Etches RJ (1990) Production of somatic and germline chimeras in the chicken by transfer of early blastodermal cells. Development 108: 185-189

Pierce GB, Lewellyn AL and Parchment RE (1989) Mechanism of programmed cell death in the blastocyst. Proc. Natl. Acad. Sci. USA 86: 3654-3658

Potchinsky MB, Muscarella DE, Hemendinger RA and Bloom SE (1995) Differential sensitivity of B-lineage lymphocytes compared to T-lineage lymphocytes to mitomycin C-induced DNA damage involving cell cycle inhibition and apoptosos. In Vitro Toxicol. 8: 389-402

Romanoff AL (1960) The Avian Embryo, The Macmillan Co., NY

Romanoff AL (1972) Pathogenesis of the avian embryo: an analysis of causes of malformations and prenatal death. Wiley-Interscience, NY

Samali A and Cotter TG (1996) Heat shock proteins increase resistance to apoptosis. Exp. Cell Res. 223: 163-170

Sanders EJ, Torkkeli PH and French AS (1997a) Patterns of cell death during gastrulation in chick and mouse embryos. Anat. Embryol. 195: 147- 154

Sanders EJ, Prasad S, Hu N and Wride MA (1997b) Cell death in the gastrulating chick embryo: potential roles for tumor necrosis factor- $\alpha$. Cell Death Differ. 4: 188-199

Schaefer El, Morimoto RI, Theidorakis NG and Seindenfeld J (1988) Chemical specificity for induction of stress response genes by DNA-damaging drugs in human adenocarcinoma cells. Carcinogenesis 9: 1733-1738

Vilagrasa X, Mezquita C and Mezquita J (1997) Differential expression of bcl-2 and $b c l-x$ during chicken spermatogenesis. Molec. Reprod. Dev. 47: 26-29

Wei Y-Q, Zhao X, Kariya U, Teshigawara K and Uchida A (1995) Inhibition of proliferation and induction of apoptosis by abrogation of heat-shock protein (HSP) expression in tumor cells. Cancer Immunol. Immumother. 40: 73-78

Weil M, Jacobsen MD, Coles HSR, Davies TJ, Gardner RL, Raff KD, Raff MC (1996) Constitutive expression of the machinery for programmed cell death. J. Cell Biol. 133: $1053-1059$

Zagris N and Matthopoulos D (1986) Differential heat shock gene expression in the chick blastula. Roux's Arch. Dev. Biol. 195: 403-407

Zamsami N, Susin SA, Marchetti P, Hirsch T, Gomez-Moterrey I, Castedo M and Dromer G (1996) Mitochondrial control of nuclear apoptosis. J. Exp. Med. 183: $1533-1544$ 